\title{
Appendix A for
}

\section{Industrial Renewal in the 21st Century: Evidence from U.S. Cities}

\author{
Thor Berger
}

\section{Carl Benedikt Frey}

This appendix presents additional material and results referred to in Industrial Renewal in the $21^{\text {st }}$ Century: Evidence from U.S. Cities. Section one provides examples of new technologyrelated industries that appeared for the first time between 2000 and 2010. Section two presents worker-level regressions, showing that skilled workers are more likely to be employed in new industries. Section three provides additional robustness checks that are referred to in the main paper. Finally, section four graphically shows differences in new industry creation across the 722 U.S. Commuting Zones.

\section{Examples of New Industries}

The paper focuses on industries that have been created due to the arrival of new technologies, eliminating industry titles that have appeared due to changing consumer preferences, import substation, or reclassifications. Specifically, 84 titles associated with changing consumer preferences, 7 titles stemming from import substitution, 69 titles that are reclassifications or splits are excluded in the main analysis. In addition, 25 titles corresponding to individual companies or public industries and 27 titles constituting residual titles (e.g., where the industry was "not specified") were also excluded from the sample.

Table A1 shows examples of detailed industries that experienced significant additions of new industry titles in the 2000s. In the Electronic auctions industry, for example, close to 67 percent of all industry titles in the 2010 Index appeared for the first time between 2000 and 2010. Importantly, while these industries employ only a small fraction of the U.S. workforce, they are substantially more skill-intensive than other industries. Furthermore, workers in industries that experienced rapid technological change earn much higher wages: the average wage for workers in detailed industries with at least one new industry title is $\$ 67,146$; more than twice the U.S. median wage. ${ }^{1}$ Consistent with a vast literature suggesting that technological advances over recent decades have favored relatively skilled workers, these results are suggestive of a substantial wage premium for workers that select into new industries.

\section{Characteristics of Workers in New Industries}

To examine the characteristics of workers in new industry, OLS regressions of the following form are estimated:

$$
n_{i}=\alpha+\mathbf{X}_{\mathbf{i}}+\varepsilon_{i}
$$

\footnotetext{
${ }^{1}$ To evaluate if these wage differences are simply the effect of higher average education in these industries, wage regressions for the 1.2 million workers in the 2010 ACS sample were estimated, controlling for demographic and educational characteristics. In such regressions, the fraction of new industry titles, in the industry that a worker is employed, is a statistically significant and positive predictor of a worker's wage.
} 
where $n$ is the probability (scaled to a percentage) that a worker $i$ is employed in a new industry, $\alpha$ is a constant, $\mathbf{X}_{\mathbf{i}}$ includes a number of individual characteristics, and $\varepsilon$ is a random error term.

Table A2 shows that education is a quantitatively important predictor of workers shifting into new industries: the estimate in column 1 implies that, relative to a worker without any degree, a worker with a bachelor's degree is 0.5 percentage points more likely to be employed in a new industry. Workers with a master's degree or Ph.D. are even more likely to be employed in a new industry. Column 2 explores the role of different types of skills, as reflected in workers' field of degree. For any given level of education, workers with a STEM degree are more likely to select into new industries. ${ }^{2}$ Finally, workers in new industries are on average relatively younger and more likely male.

It is of course possible that if more educated workers seek out sectors of the economy that are more skill-intensive, such as professional services, and these sectors simultaneously experience higher additions of new industry titles, this correlation may drive the results. It is therefore reassuring that when looking only at selection into new industries within major industry groups, the results are similar (column 3).

\section{Additional Results and Robustness Checks}

Table A3 provides additional robustness checks of the main results reported in the paper (see Table 1). Column 1 shows that results are similar when all $722 \mathrm{CZs}$, covering also the rural United States, are included though magnitudes are larger in the urban sample. Similarly, excluding Santa Fe and San Jose, with substantially higher employment in new industries relative to other comparable cities (see Figure 1 in the paper), does not alter the interpretation of the results, although estimated magnitudes are slightly reduced.

Another concern is that a historical dependence on manufacturing may have caused some cities to lose their ability to reinvent themselves. Column 4 controls for the share of employed workers, 16 years and older, working in manufacturing in 2000 and exposure to Chinese imports during the 1990s, which slightly increases the effect of human capital on new industry creation.

Furthermore, the main focus in the paper is on new industries that have emerged following the arrival of new technologies. If there is a mechanical correlation between skills and new industry classifications, however, non-technology industry titles should also appear more frequently in skilled cities. Column 4 presents results from this placebo check, which examines the link between new industries that are not related to new technologies and concentrations of skilled workers. ${ }^{3}$ Reassuringly, there is no relationship between the appearance of non-technology related industries and differences in human capital across cities; the coefficient is close to zero and not statistically significant.

Finally, the results are not sensitive to using alternative definitions of new industry titles. Column 5 excludes all duplicate titles, which may inflate the actual number of industry titles

\footnotetext{
${ }^{2}$ Degrees within the following fields are defined as belonging to STEM: Communication Technologies; Computer and Information Sciences; Engineering; Engineering Technologies; Biology and Life Sciences; Mathematics and Statistics; Military Technologies; Nuclear, Industrial Radiology, and Biological Technologies; Transportation Sciences and Technologies.

${ }^{3}$ Non-technology related industries are defined simply as all new industry titles, less the 71 technology-related titles that we use in our main analysis.
} 
in the sample. ${ }^{4}$ Column 6 then makes the unrealistic assumption that all 283 industry titles in the 2010 Index that do not match a title in the 2000 edition reflect truly new industries, by including all new titles when calculating the dependent variable (column 6). Despite these alternative assumptions the main results remain. Taken together, these results provide robust evidence for new technology-related industries appearing in cities that are dense in skills.

\section{The Geography of Industrial Renewal}

Figure A1 shows the share of workers in new industries across the $722 \mathrm{CZs}$ of the conterminous United States. New industries are especially prevalent in the Western U.S.---in particular in California---and along the northeastern coast. By contrast, the appearance of new industries is lower on average in the Midwest and within the Rust Belt. There is also substantial variation in new industry creation across the Sun Belt. While few new industries have emerged in the South, the Southwest exhibits relatively high fractions of new industries. Furthermore, new industries have mainly appeared in urban locations: cities experienced more than 40 percent higher growth in new industry employment between 2000 and 2010 than rural areas.

\footnotetext{
${ }^{4}$ For example, "Auction sites, internet" and "Internet auction sites" both appeared for the first time between 2000 and 2010 in the Index. In this regression "Auction sites, internet", for example, is excluded while "Internet auction sites" is included.
} 


\begin{tabular}{|c|c|c|c|c|c|}
\hline Detailed Industry & $\begin{array}{l}\text { New Industry } \\
\text { Titles }\end{array}$ & $\begin{array}{l}\text { Share of U.S. } \\
\text { Empl. }\end{array}$ & $\begin{array}{l}\text { College } \\
\text { Share }\end{array}$ & $\begin{array}{l}\text { Avg. } \\
\text { Wage }\end{array}$ & Examples of New Titles \\
\hline (1) & (2) & (3) & (4) & (5) & (6) \\
\hline $\begin{array}{l}\text { Internet publishing and broadcasting } \\
\text { and web search portals }(6672)\end{array}$ & $85.7 \%$ & $0.06 \%$ & $69.6 \%$ & $\$ 81138$ & $\begin{array}{l}\text { Internet video broadcast } \\
\text { sites; Social Networking } \\
\text { Services; Internet game } \\
\text { sites }\end{array}$ \\
\hline Electronic auctions (5591) & $66.6 \%$ & $0.01 \%$ & $52.2 \%$ & $\$ 47257$ & Internet auction sites \\
\hline $\begin{array}{l}\text { Computer systems design and related } \\
\text { services }(7380)\end{array}$ & $7.1 \%$ & $1.34 \%$ & $69.9 \%$ & $\$ 80324$ & $\begin{array}{c}\text { Computer programming } \\
\text { service; Logistics services; } \\
\text { Web page designing, exc. } \\
\text { internet }\end{array}$ \\
\hline Avg. Across U.S. Industries & $1.27 \%$ & - & $28.6 \%$ & $\$ 44333$ & - \\
\hline
\end{tabular}

Notes: This table presents examples of detailed industries (column 1) that experienced large additions of new industry titles (column 2, with examples in column 6), identified from a comparison of the 2000 and 2010 editions of the U.S. Census Bureau's Alphabetical Index of Industries. Industry characteristics are calculated from the 2010 ACS sample, for employed and non-institutionalized workers, aged 18-65. College shares (column 4) are calculated as the percentage of workers, aged above 25, with a bachelor's, master's, professional or doctoral degree. Average wages are based on an arithmetic average of yearly wages (column 5).

Table A1. Examples of New Industries, 2000-2010. 
(1)

$0.499 * * *$

$(0.013)$

$0.536^{* * *}$

(0.019)

$-0.058 * * *$

$(0.022)$

$0.728 * * *$

(0.039)

STEM Field (=1)

Age

Married (=1)

Asian (=1)

Black (=1)

(0.000)

$-0.225 * * *$

(0.008)

$0.044 * * *$

(0.009)

$0.458 * * *$

(0.025)

$0.040 * * *$
(2)

(3)

$0.053 * * *$

$0.233 * * *$

(0.018)

$-0.433 * * *$

(0.023)

(0.024)

$0.579 * * *$

(0.036)

(0.040)

$0.597 * * *$

(0.022)

(0.019)

$-0.004 * * *$

$-0.004 * * *$

$-0.002 * * *$

(0.000)

(0.000)

$-0.213 * * *$

$-0.074 * * *$

(0.008)

(0.009)

$0.038 * * *$

$0.082 * * *$

(0.009)

(0.008)

$0.402 * * *$

$0.368 * * *$

(0.025)

(0.021)

$0.038 * * *$

$0.034 * * *$

(0.014)

(0.014)

(0.012)

Yes

Industry FE?

No

No

$1,174,972$

Notes: This table presents OLS estimates from regressing the percentage probability that a worker is employed in a new industry on a number of individual characteristics based on the 2010 ACS sample, including employed and non-institutionalized workers, aged 18-65. Column 3 adds a full set of major industry fixed effects. Statistical significance based on robust standard errors is denoted by: $* * * \mathrm{p}<$ $0.01, * * \mathrm{p}<0.05, * \mathrm{p}<0.10$.

Table A2. Characteristics of Workers in New Industries, 2010. 
Outcome: \% of Workers Employed in New Industries

\begin{tabular}{|c|c|c|c|c|c|}
\hline & \multicolumn{2}{|c|}{ Alternative samples } & \multicolumn{3}{|c|}{ Alternative titles } \\
\hline & Incl. Rural & Excl. Outliers & Placebo & No duplicates & All \\
\hline & (1) & (2) & (3) & (4) & (5) \\
\hline $\begin{array}{l}\text { \% with College Degre } \\
2000\end{array}$ & $\begin{array}{c}0.010 * * * \\
(0.003)\end{array}$ & $\begin{array}{c}0.015^{* * *} \\
(0.002)\end{array}$ & $\begin{array}{l}-0.004 \\
(0.006)\end{array}$ & $\begin{array}{l}0.013 * \\
(0.008)\end{array}$ & $\begin{array}{c}0.015 * * * \\
(0.002)\end{array}$ \\
\hline City Characteristics? & Yes & Yes & Yes & Yes & Yes \\
\hline State FE? & No & No & No & No & No \\
\hline Observations & 722 & 319 & 321 & 321 & 321 \\
\hline R-squared & 0.27 & 0.46 & 0.06 & 0.52 & 0.19 \\
\hline
\end{tabular}

Notes: This table presents robustness checks of the main results presented in the paper, where the outcome variable is the percentage of workers employed in new industries (see Table 1). Column 1 includes all rural CZs, in addition to the 321 urban CZs. Column 2 excludes San Jose and Santa Fe from the sample. Columns 3-5 uses alternative definitions of new industries, explained in further detail in the main text. Statistical significance based on robust standard errors clustered at the state-level is denoted by: $* * * p<0.01, * * p<0.05, * \mathrm{p}<0.10$.

\section{Table A3: Robustness Checks.}




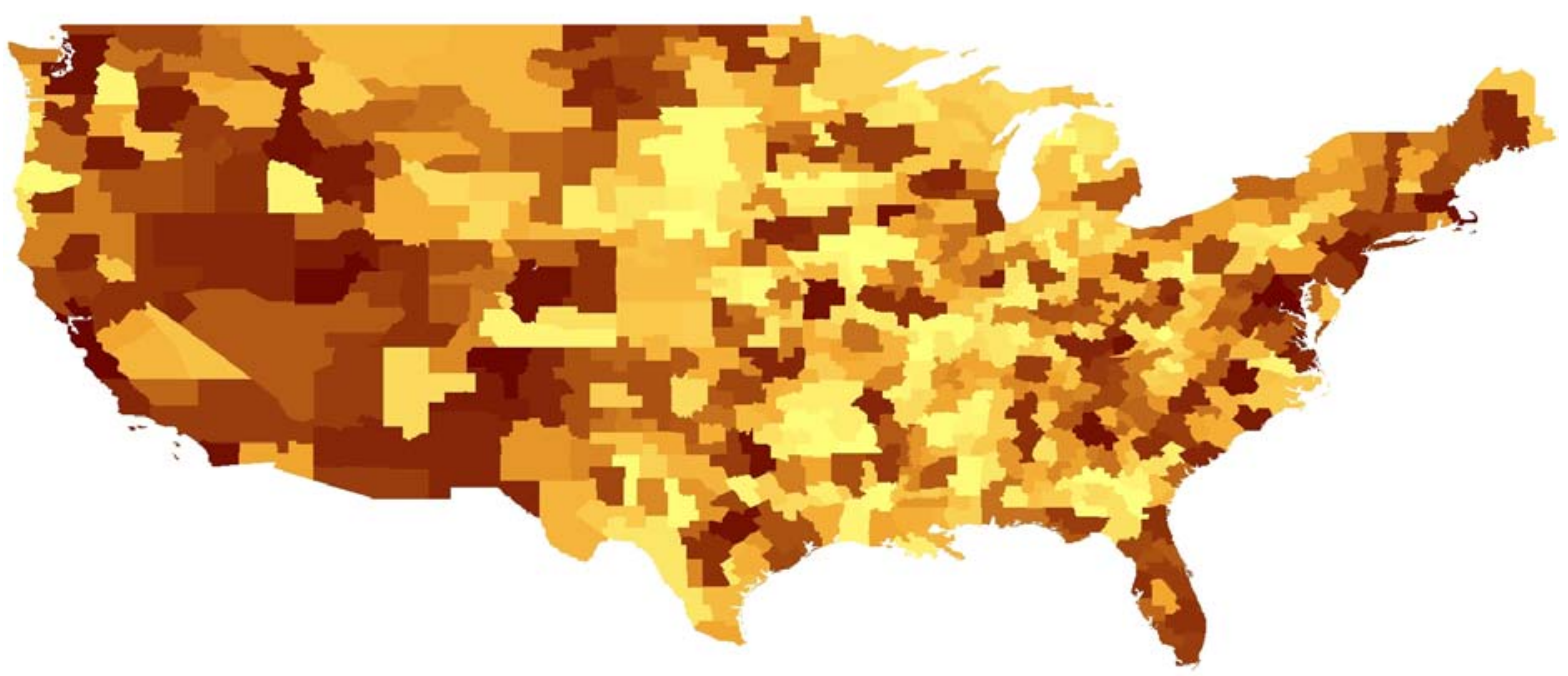

Notes: This figure shows the share of workers in employed in technology-related industries that were created between 2000 and 2010, for the $722 \mathrm{CZs}$ of the conterminous United States. Darker shades correspond to a higher fraction of workers in new industries.

Figure A1. The Geography of New Industries, 2010. 